\title{
Investigation of Electromagnetic Properties of Tool Hard Alloys under the Influence of High Temperatures
}

\author{
E.V. Artamonov ${ }^{1, a^{*}}$, A.M. Tveryakov ${ }^{1, b}$ and A. S. Shtin ${ }^{1, c}$ \\ ${ }^{1}$ Industrial University of Tyumen, Volodarskogo 38, Tyumen, Russia \\ aevgart2014@mail.ru, btveryakov@mail.ru, cshtin_as@mail.ru
}

Keywords: Hard Alloys, Metalworking, Maximum Working Capacity Temperature, Electromagnetic Properties, Cutting

\begin{abstract}
The article shows the developed installation for determination of temperature of maximum operability of replaceable cutting hard-alloy plates on the basis of study of change of electromagnetic properties. The method of research is given. Tests of images were carried out to time of heating of the replaceable cutting plates from solid B35 alloy. The heating temperature interval was selected according to the temperature mode of the process of cutting difficult materials. Heating was carried out to $1000^{\circ} \mathrm{C}$. The results of the study were obtained to determine the temperature of maximum operability of replaceable cutting hard alloy plates based on the study of the change in electromagnetic properties for alloy B35 amounted to $460-730^{\circ} \mathrm{C}$.
\end{abstract}

\section{Introduction}

Today, under the conditions of sanctions, the Russian Federation needs more than ever the development of energy-saving technologies in various industries.

Metallurgy does not stand still, recently new brands of materials have appeared that have characteristics in terms of strength, hardness, ductility, heat resistance many times superior to their analogues, for example, Russian grades of alloys such as GDP, American "martensite."

Studies have shown that the selection of tool material, as well as the assignment of processing (cutting) modes, are the main problems in the processing of steels and alloys included in the group of difficult-to-process materials [1].

When assigning cutting modes for new materials, tool companies conduct tests for destruction of replaceable cutting inserts during cutting, and the obtained numerical values are published in catalogs [2]. But as practice shows, these numerical values do not always correspond to optimal cutting modes. In practice, the mode conditions for the tool are divided into machinability groups [3].

In their works, the problem of ensuring the fullest life of a cutting tool from various positions was studied: Vasin S.A. [4], Grigoriev C.N. [5], Coarse S.V. [6], Carceanu, I., Cosmeleat.0., G. [7], Ferri, C. [8], Kümmel, J. [9], Munish Kumar Gupta [

A literature analysis of the work of world-renowned scientists in the field of mechanical blade processing of metals by cutting showed that the temperature factor has a resulting effect on the cutting process of difficult-to-process materials. [4-18].

Tool materials (IM), like other materials, have physical and mechanical properties that can change under the influence of external factors. These properties have a decisive effect on the health and resource of the tool made of these materials. Studies have shown that the physical and mechanical properties of tungsten hard alloys in the process of operation, namely in the process of cutting hard-to-process materials under the influence of high temperatures, vary symmetrically [19]. The study of the processes inside the tool materials, including tungsten hard alloys, will allow, on the basis of a scientifically sound method, to determine and assign the operating modes 
of this material taking into account its internal changes. This will increase the life of the cutting tool and create conditions under which the cutting tool will have maximum cutting properties when processing difficult materials [20].

The purpose of the work: to conduct research on the change in the electromagnetic field of eddy currents arising in replaceable cutting plates made of tungsten hard alloy B35 in the temperature range characteristic of the cutting process.

To achieve the goal, the following tasks were set and solved.

1. Carry out a literary review, as well as an analysis of existing work on the problem of rational selection of a tool material, as well as the purpose of cutting modes.

2. Conduct experimental studies of the change in the electromagnetic field of eddy currents occurring in solid alloys B35 under the influence of high temperatures characteristic of the cutting process.

\section{Research methodology}

To solve the second problem, it is necessary to conduct laboratory studies of changes in the magnetic field of eddy currents arising in replaceable cutting plates made of tungsten hard alloy B35. An analysis of existing solutions showed that such devices that meet our requirements do not exist. One of the requirements for the device is the possibility of using a replaceable multifaceted hard alloy plate as a test sample in the delivery state, to maximize the approximation of the results to real conditions.

During the development of the laboratory plant, a literary review was carried out, which showed that at the moment non-destructive testing methods of technological facilities have been widely used.

The "eddy current" [21] method of nondestructive testing is suitable for studies of internal changes occurring inside tool materials), with the possibility of testing samples in the state of supply (replaceable cutting hard alloy plates (SMTP). This type of nondestructive testing will allow conducting studies on samples in the form of replaceable cutting inserts in the state of supply, which allows reducing the time for the production of special samples. Also, this advantage allows us to bring the conditions in which laboratory studies are carried out closer to real conditions.

As the test images, SMTP from instrumental hard alloy B35 in the delivery state were chosen.

The research was carried out at a special laboratory installation, which was based on the eddy current method of non-destructive testing. The diagram of the proposed installation is shown in Figure 1 . The laboratory plant is a system of instruments for measuring changes in the magnetic field of eddy currents arising in ferromagnets.

\section{Results and discussion}

It is recommended to use SMTP as the test objects in the delivery state, since the dimensions of the used coil with heat-insulating coating are limiting. When changing the coil, it is allowed to examine other forms of factors on samples. 


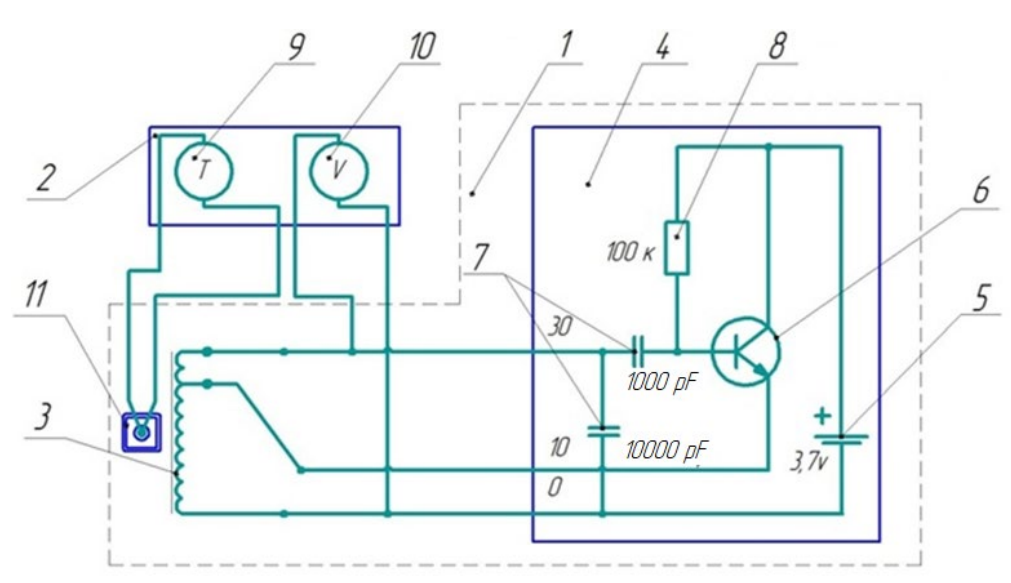

Fig. 1. Scheme of the plant developed by the authors to determine the temperature of maximum operability of replaceable cutting hard alloy plates by electromagnetic properties: 1- Selfoscillating circuit; 2-Housing; 3-Coil; 4- PCB; 5- Power supply; 6- Transistor; 7-Capacitor; 8Resistance; 9 - Thermometer; 10 - Voltmeter; 11-Replaceable cutting insert.

The unit includes self-oscillating circuit (AC) and instrument board. To measure the quantitative complex characteristic of the change in the magnetic field of BT (eddy currents), a multi-voltmeter is used, and a digital thermometer was used to measure the state of temperature throughout the experiment. Electronic part of device represents electronic circuit consisting of two series-connected capacitors, resistance, transistor and power supply unit. AK is made in the form of autotransformer, like eddy current converter excitation winding. The winding is coated to prevent damaging effect of object heating and destruction of the winding itself.

Tests of the samples were carried out during heating of replaceable cutting inserts made of tungsten hard alloy B35.

The heating temperatures were selected in the range up to $1000^{\circ} \mathrm{C}$. The studies were carried out as follows. The sample was heated, in our case the sample is a replaceable cutting hard alloy plate in the supply state. Then magnetic field is applied to analysed sample by non-contact method.

Changes in values indicating internal changes of the hard alloy are recorded on the voltmeter. The results are displayed on the PC monitor screen.

Based on the results of experimental studies, tables of the results were compiled. In them, with an interval of $10^{\circ} \mathrm{S}$, the corresponding values of the magnetic field of eddy currents induced in replaceable cutting plates made of tungsten hard alloy B35 are indicated.

Using the capabilities of the mathematical apparatus of the MS Excel software product, the polynomial dependencies of the obtained data on the heating temperature were built, shown in Figure 2. The temperature range (Q) (Figure 3) in which the experimental studies were performed corresponds to the temperature range characteristic of the cutting process. 


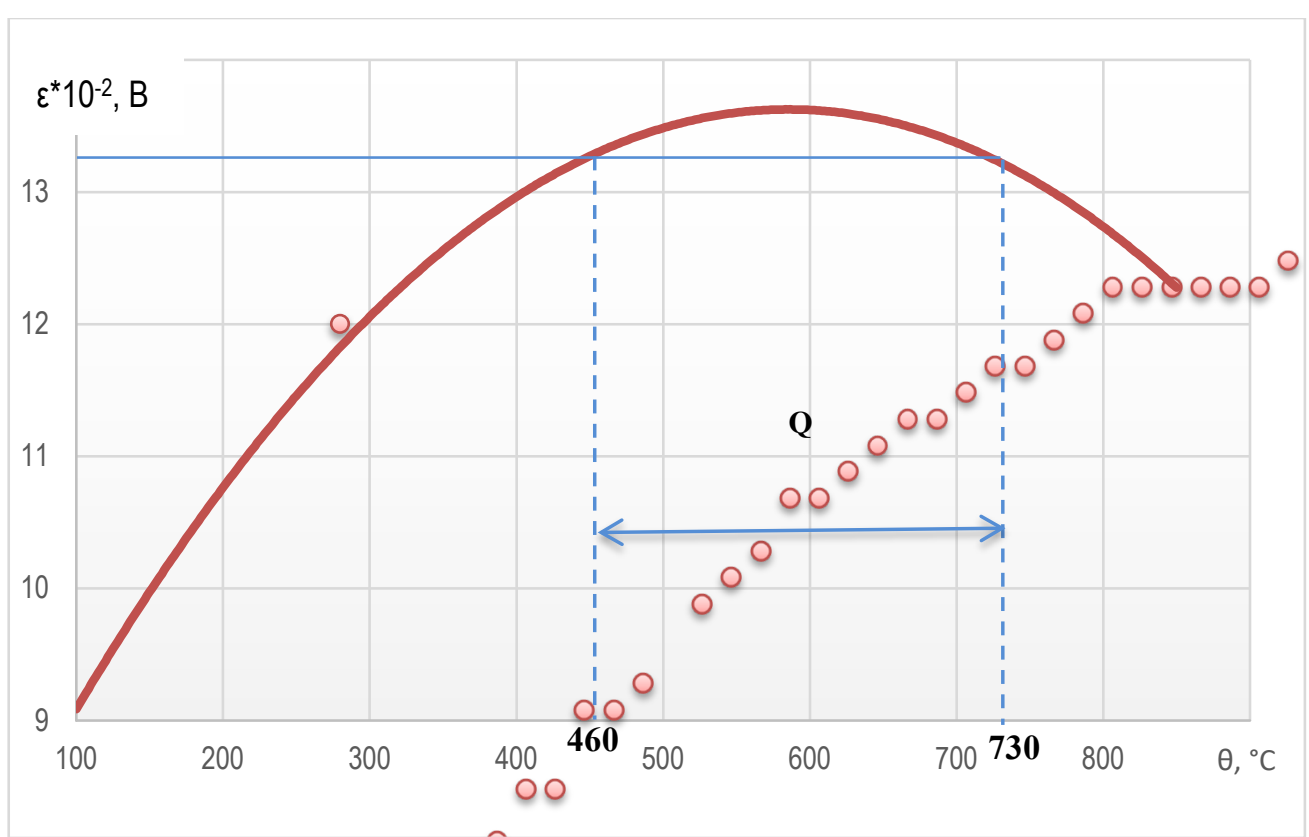

Fig. 2. Obtained one-parameter dependence of change of AK EMF values during the alloy experiment B35 under the influence of temperatures

The obtained graphical dependence, where a polynomial is selected as the approximating curve, is processed according to the rules of engineering studies, in accordance with $5 \%$ of the error allowed for such calculations.

To determine the boundary of the temperature range, a special technique is used. From the value of the maximum magnetic field, a 5 percent interval is deposited. A line parallel to the temperature axis is drawn through this point through the entire graph field. The points where the line intersects the line (which) of the graph are taken to be outside the range you want. From the obtained points, we draw projection lines on the temperature axis. The obtained temperature interval is taken as the interval of maximum life of replaceable cutting inserts made of hard alloy B35.

\section{Conclusions}

It is allowed to use the tool in the entire temperature range, but from the technological point of view, it is recommended to adhere to the maximum temperature, since it corresponds to the maximum permissible cutting speed.

During the work, experimental studies were carried out on changing the electromagnetic field of eddy currents arising in solid alloys of grade B35, under the influence of high temperatures characteristic of the cutting process, which made it possible to obtain a temperature interval for changing the electromagnetic properties of $460 \div 730^{\circ} \mathrm{C}$.

\section{References}

[1] E.V. Artamonov, Strength and operability of replaceable hard alloy plates of prefabricated cutting tools, Tyumen, Vector Buk, 190. 2003 p. 135.

[2] N.N. Zorev Untersuchung der Kintakt-spannunger auf den Arbeits-flachen des Werkzeugs miteiner Schneidenabrundung, in: N.N. Zorev, M.H. Uteshev - Berichte der Internationalen Forschungesgemein-schaft fur mechanische produktionstechniktionstechnik Vol. 20-1 Schweiz, 1971, pp. 31-32. 
[3] Information on http://www.kzts.ru/core/user_files/psm-2014.pdf

[4] S.A. Vasin Cutting materials: Thermomechanical approach to the system of relationships in cutting: a textbook for technical universities, in: S.A. Vasin, A.S. Vereshchak, V.S. Kushner M.: Publishing House MSTU named after N.E. Bauman, 2001, p. 448

[5] V.A. Grechishnikov Formation processes and instrumental technique, in: V.A. Grechishnikov, N.A. Chemborisov, V.B. Stupko, D.T. Safarov, O.B. Kuchina, S.N. Grigoriev, A.G. Schirtladze. - Old Oskol: TNT, 2012. p. 328.

[6] V.V. Lapshin, Machining of linear negative matrices for fresnel lenses and prisms, in: V.V. Lapshin, E.M. Zakharevich, S.V. Grubyi - Russian engineering research, Allerton Press, Inc, New York, Vol. 36.10, 2016 pp. 826-830. https://doi.org/10.3103/S1068798X16100105

[7] I. Carceanu, G. Cosmeleată, B. Ghiban, M. Balanescu, I. Nedelcu, High performance composite materials created through advanced techniques, Materiale Plastice Vol. 44, Issue 4, 2007, pp. 321-325.

[8] C. Ferri, T. Minton, S.B. Ghani, K. Cheng, Internally cooled tools and cutting temperature in contamination-free machining. Proceedings of the Institution of Mechanical Engineers, Part C: Journal of Mechanical Engineering Science Vol. 228, Issue 1, 2014, pp. 135-145. https://doi.org/10.1177/0954406213480312

[9] J. Kümmel, D. Braun, J. Gibmeier, J. Schneider, C. Greiner, V. Schulze, A. Wanner, Study on micro texturing of uncoated cemented carbide cutting tools for wear improvement and built-up edge stabilization. Journal of Materials Processing Technology Vol. 215, 2015, pp. 6270. https://doi.org/10.1016/j.jmatprotec.2014.07.032

[10] Munish Kumar Gupta, Machining of Aerospace Material - Ti (grade-2) alloy: Modelling and Optimization/ Pardeep Kumar Sood, Gurraj Singh, Vishal S. Sharma Sustainable// Journal of Cleaner Production. https://doi.org/10.1016/j.jclepro.2017.01.133

[11]K.S. Murthy, I. Rajendran, Optimization of end milling parameters under minimum quantity lubrication using principal component analysis and grey relational analysis. Journal of the Brazilian Society of Mechanical Sciences and Engineering Vol. 34, Issue 3, 2012, pp. 253-261. https://doi.org/10.1590/S1678-58782012000300005

[12] R. Neugebauer, C. Hochmuth, G. Schmidt, M. Dix, Energy efficient process planning based on numerical simulations. Advanced Materials Research 2011, Vol. 223, pp. 212-221, 17th CIRP Conference on Modelling of Machining Operations; Sintra; Portugal, 2011. https://doi.org/10.4028/www.scientific.net/AMR.223.212

[13]A. Nurulamin, I. Jaafar, W. Zubaire Role of discrete nature of chip formation and natural vibrations of system components in chatter formation during metal cutting, IIUM Engineering Journal. 2010, Vol. 11, pp. 124-126. https://doi.org/10.31436/iiumej.v11i1.53

[14] S. Tangjitsitcharoen, T. Moriwaki Intelligent monitoring and identification of cutting states of chips and chatter on CNC turning machine, Journal of Manufacturing Processes. 2008, Vol.10, pp. 40-46. https://doi.org/10.1016/j.jmatprotec.2007.04.043

[15] A. Patwari, Investigations of formation of chatter in a non-wavy surface during thread cutting and turning operations, in: A. Patwari, N. Amin, W. Faris - Text : electronic, Advanced 
Materials Research. 2010, Vol.83, pp. 637-645.

https://doi.org/10.4028/www.scientific.net/AMR.83-86.637

[16] W. Tillmann, C. Schaak, D. Biermann, R. Abmuth, S. Goeke, Robot based deposition of WC-Co HVOF coatings on HSS cutting tools as a substitution for solid cemented carbide cutting tools. IOP Conference Series: Materials Science and Engineering,Volume 181, Issue 1, 17 March 2017, Vol. 2011 19th Chemnitz Seminar on Materials Engineering; Chemnitz; Germany; 16 March 2017- 17 March 2017. https://doi.org/10.1088/1757-899X/181/1/012011

[17] H. Zhang, Z.Z. Fang, Q. Lu, Characterization of a bilayer WC-Co hardmetal using Hertzian indentation technique. International Journal of Refractory Metals and Hard Materials, Vol. 27, Issue 2, March 2009, pp. 317-322. https://doi.org/10.1016/j.ijrmhm.2008.07.014

[18] C. L. Zhang, A hybrid approach of ANN and HMM for cutting chatter monitoring, in: C. L. Zhang, X. Yue, Y. T. Jiang, - Text : electronic, Advanced Materials Research. 2010, Vol.97, pp. 3225-3232. https://doi.org/10.4028/www.scientific.net/AMR.97-101.3225

[19]E.V. Artamonov, Installation for diagnostics of temperature of maximum operability of replaceable cutting inserts based on change of electromagnetic properties of hard alloys, in: E.V. Artamonov, A.M. Tveryakov, A.S. Shtin Control. Diagnostics. 2018. Vol.12. pp. 54-57. https://doi.org/10.14489/td.2018.12.pp.054-057

[20]E.V. Artamonov Determination of Temperature of Maximum Working Capacity of Tool Hard Alloys, in: E.V. Artamonov, A.M. Tveryakov, A.S. Shtin - Text : electronic, Obrabotka metallov-metal working and material science, - 2018. - Vol. 20.3, pp. 47-57.

https://doi.org/10.17212/1994-6309-2018-20.3-47-57

[21]E.V. Artamonov Development of installation elements for determining the temperature of maximum operability of cutting elements from hard alloys, in: E.V. Artamonov, A.M.

Tveryakov, A.S. Shtin .Transport and mechanical engineering of Western Siberia. 2018. Vol. 1. - pp. 31-38. 